\title{
Crime Rates in a Pandemic: the Largest Criminological Experiment in History
}

\author{
Ben Stickle ${ }^{1}$ (D) Marcus Felson $^{2}$ (D) \\ Received: 29 May 2020 / Accepted: 11 June 2020 / \\ Published online: 16 June 2020 \\ (C) Southern Criminal Justice Association 2020
}

\begin{abstract}
The COVID-19 pandemic of 2020 has impacted the world in ways not seen in generations. Initial evidence suggests one of the effects is crime rates, which appear to have fallen drastically in many communities around the world. We argue that the principal reason for the change is the government ordered stay-at-home orders, which impacted the routine activities of entire populations. Because these orders impacted countries, states, and communities at different times and in different ways, a naturally occurring, quasi-randomized control experiment has unfolded, allowing the testing of criminological theories as never before. Using new and traditional data sources made available as a result of the pandemic criminologists are equipped to study crime in society as never before. We encourage researchers to study specific types of crime, in a temporal fashion (following the stay-at-home orders), and placed-based. The results will reveal not only why, where, when, and to what extent crime changed, but also how to influence future crime reduction.
\end{abstract}

Keywords COVID-19 Crime rates $\cdot$ Coronavirus response $\cdot$ Routine activities $\cdot$ Rational choice Crime

The COVID-19 pandemic of 2020 is unquestionably one of the most significant worldwide events in recent history, impacting culture, government operations, crime, economics, politics, and social interactions for the foreseeable future. One unique aspect of this crisis is the governmental response of issuing legal stay-at-home orders to attempt to slow the spread of the virus. While these orders varied, both in degree and timing, between countries and states, they generally began with strong encouragement for persons to isolate themselves voluntarily. As the magnitude of the crisis grew,

Ben Stickle

Ben.stickle@mtsu.edu

1 Department of Criminal Justice Administration, Middle Tennessee State University, Murfreesboro, TN 37132, USA

2 Texas State University, San Marcos, TX, USA 
governments began legally mandating persons to stay-at-home to reduce the transmission rate of the virus. There were, of course, exceptions; workers who were deemed 'essential,' such as those in the fields of medicine, finance, public safety, food production, transportation, and in other miscellaneous industries did not have to abide by these orders to the degree to which the general public did.

Nevertheless, practically overnight, the entire country ceased or significantly reduced day-to-day travels, eliminating commutes from home to work, as well as leisure activities, shopping trips, social gatherings, the ability to dine out, and more. One poll in late March found that $90 \%$ of Americans, including essential workers, were 'staying at home as much as possible' (Washington Post-ABC, 2020). The 'stay-at-home' mandates brought about the most wide-reaching, significant, and sudden alteration of the lives of billions of people in human history. Across the United States and around the world, a positive byproduct (Fattah, 2020) of these unprecedented events is a dramatic drop in crime rates.

\section{Initial Crime Data}

Several researchers have made initial examinations into how crime rates have fluctuated in the advent of COVID-19. The results have been mixed, to say the least, especially when comparing broad categories of crime across different cities and with different methods and periods of study. However, these initial academic studies are intrinsically valuable and deserve to be mentioned here.

One of the earliest studies with perhaps the most striking results was by Shayegh and Malpede (2020), which identified an overall drop in crime in San Francisco of $43 \%$ and Oakland of about $50 \%$ following city issuance of some of the most restrictive and early stay-at-home orders in the US, beginning March 16th, 2020 and the two weeks after.

Surprisingly, significant results are also clearly seen when examining specific crimes against retailers in crime in Los Angeles. Pietrawska, Aurand, and Palmer (2020a) found a $64 \%$ increase in retail burglary, while city-wide burglary rates were down $10 \%$. Similarly, Pietrawska, Aurand, and Palmer (2020b) identified a five-week change in crimes occurring at restaurants in Chicago, a $74 \%$ reduction, while city-wide crime declined $35 \%$. Continuing their study of crime rates in the pandemic outside of a retail focus, Pietrawska, Aurand, and Palmer (2020c) compared crimes against persons and crimes against property in four cities for ten weeks, finding sharp variations from week to week and within different crime types.

Another early study by Ashby (2020a) of eight large US cities during the first few weeks of the crisis (January to March 23rd - before some states and areas implemented stay-at-home orders) found disparate impacts by crime type and location. For example, burglary declined in Austin, Los Angeles, Memphis, and Scan Francisco, but not in Louisville or Boston. Conversely, serious assaults in public declined in Austin, Los Angeles, and Louisville, but not other cities.

Felson, Jiang, and $\mathrm{Xu}$ (2020) examined burglary in Detroit during three periods, representing data before stay-at-home orders were in place and two periods under orders (March 10th to March 23rd and March 24th to March 31st). Their findings indicated an overall $32 \%$ decline in burglary, with the most substantial change in the third period. However, the decline was more significant in block groups of higher residential parcels than in mix-use land areas. 
Campedelli et al. (2020) analyzed crime in Los Angeles in two time periods (the first ending March 16th and the second ending March 28th) using Bayesian structural timeseries models to estimate what crime would have been if the COVID-19 pandemic had not occurred. Comparing the actual crime data against the estimated 'sans-pandemic' data, the first model found an overall crime reduction of $5.6 \%$ during the pandemic. Likewise, the second model (ending March 28th) showed a 15\% reduction. Specifically, researchers found that overall crime rates significantly decreased, particularly when referencing robbery $(-24 \%)$, shoplifting $(-14 \%)$, theft $(-21 \%)$, and battery $(-11 \%)$. However, burglary, domestic violence, stolen vehicles, and homicide remained statically unchanged.

While not explicitly measuring crime rates, studies of calls for police service can function as an indirect measure of crime in a given area. Early studies of calls for service during the pandemic present mixed results. Lum, Maupin, and Stoltz (2020) found that 57\% of 1000 agencies surveyed in the United States and Canada reported a reduction in calls for service in March of 2020. Ashby (2020b), on the other hand, found no discernible difference in forecasted calls for service in 10 large US cities between the first identified cases of COVID-19 in the US throughout early March. However, Ashby found that once stay-at-home orders were implemented, calls for service did decline, although not evenly across call types or cities. In another study of police calls for service, Mohler et al. (2020) examined calls in Los Angeles and Indianapolis between January and mid-April; they concluded there was some impact on police calls for service but not across all crime types or places.

Internationally, Swedish researchers Gerell, Kardell, and Kindgren (2020) examined crime during the five weeks after government restrictions on activities began, observing an $8.8 \%$ total drop in reported crime despite the country's somewhat lax response (when compared to other countries' policies on restricting the public's movement). Specifically, the researchers found residential burglary fell by $23 \%$, commercial burglary declined $12.7 \%$, and instances of pick-pocketing were reduced by a staggering $61 \%$-however, there was little change in robberies or narcotics crime. In Australia, Payne and Morgan (2020) studied crime in March, finding assaults, sexual violations, and domestic violence were not significantly different from what was predicted under 'normal' conditions at the lower end of the confidence interval. They cautioned against early conclusions based on this data as the government orders came only a few weeks into the study.

These initial reports indicate that crime rates have indeed changed, but unequally across different categories, types, places, and timeframes. Among crime researchers, the featured question of this pandemic will be, "Why have crime rates fallen so dramatically?" The corollary is, "What can be learned from this experience to leverage crime reduction in the future?" The data and opportunities before every criminologist will provide near-endless research opportunities at levels never before possible, and every effort should be made to capture data and promote the study of crime. This research note aims to identify and encourage these lines of inquiry, to urge researchers to dive deeply into the data made available from the pandemic, and to provide the impetus for not only discerning why crime fell but also for how to pragmatically utilize this knowledge after the world emerges from seclusion. 


\section{Crime in Lock-Down: Theoretical Implications}

During the few hours before a legal stay-at-home order was implemented, and throughout the first few weeks that followed, it is essential to note what likely did 'not' change. As people around the world returned from frantic and stress-filled trips to stock up on food and other essentials and closed the door to their residence behind them, their biological and physiological conditions changed very little, nor did the labels attributed to them by society, friends, or family. Poverty and inequality did not disappear or increase immediately. It is unlikely that self-control dramatically increased either. There were, however, things that did change; society became more disorganized, and social influences and relationships were suddenly cut, diminished, or otherwise altered. Strain, stress, and anomie likely increased significantly as many became fearful for the future (both financially and physically) and estranged from family and friends whom they could not visit physically. Further, punitive responses to crime (i.e., deterrence) were slowed or ceased altogether as courts closed, police were encouraged to reduce contact with the public, and thousands of prisoners were released early.

With crime declining at such a significant pace and many of the often-attributed circumstances impacting crime staying consistent or in some cases increasing or decreasing in a direction opposite of what many believe drives crime, many criminological theories appear to be struggling to explain the abrupt and sweeping change. We believe the scope and nature of crime changes during the COVID-19 crisis will become a proving ground for the many theories that attempt to explain the etiology of criminal behavior. In the end, this naturally occurring experiment will advance our knowledge of crime and human behavior as no other event has ever done during the era in which criminological data were widely available.

As such, we argue that the single most salient aspect of the steep fall in crime rates during the COVID-19 pandemic are the legal stay-at-home orders (i.e., lock-down, shelter-in-place) implemented to slow the spread of the virus by promoting social distancing. Stay-at-home orders were issued by most states and legally required residence to stay within their homes except for authorized activities. Commonly, these activities included seeking health care, purchasing food and other necessary supplies, banking, and similar activities. The orders either outright closed or by de-facto closed broad swaths of the economy and impacted schools, private social gatherings, religious activities, travel, and more. In short, these orders disrupted the daily activities of entire populations and was the only variable that changed abruptly, just days before double-digit drops in crime around the world. As such, we believe, the Environmental Criminology suite of perspectives including; Rational Choice (Clarke \& Felson, 1993) and Routine Activity (Cohen \& Felson, 1979) will emerge as frontrunners in understanding the crime changes during COVID-19 and will provide insight how to influence crime in the future.

\section{A Call to Examine Crime}

Therefore, we offer a call for examining crime before, during, and after a governmentimposed stay-at-home order, that coincides with the COVID-19 pandemic. Specifically, we advocate for researchers to consider crime in the context of temporal shifts, in a place-based context, to use emerging data sources, and to study crime with specificity. 


\section{Crime Specificity}

Criminologists tend to overgeneralize about crime while underestimating the enormous specificity in offender decision making (LeClerc, \& Wortley, R. (Eds.)., 2013). Even within each crime type, the finer particulars of an offense should be studied to understand how crime patterns change and shift. Specificity is even more critical when researching crime in a pandemic as it allows for an understanding of nuanced changes, such as opportunity structure, that would otherwise be missed. For example, the changes in daily activities in the wake of the pandemic tend to decrease the population in nonresidential parts of the metropolis, while increasing the population in residential zones.

For example, the broad category of 'theft' appears to be down across many cities in the US (Ashby, 2020a). However, theft is likely not declining evenly across all categories. Consider theft in a retail context. The retail sector has experienced an $85 \%$ decline in foot traffic after the stay-at-home orders were implemented (Jahshan, 2020); many stores are closed, and thus the opportunity for shoplifting and employee theft are curtailed. Pietrawska et al. (2020a), for example, identified a $24 \%$ decline in shoplifting in Los Angeles, compared to a city-wide decline of theft at only 5\%. However, theft may persist (and even see an increase) within stores that remain open such as grocers, construction supplies, convenience stores, pharmacies, and other 'essential' retailers. These thefts may be the result of a change in offender behavior (i.e., shifting from targeting a specific store - now closed, to another that is open), due to panic buying (i.e., purchasing limits on essential products may result in theft), or impacted by reduced guardianship within the stores (e.g., short-staffed employees are more focused on service than crime prevention).

One of the most exciting illustrations of crime specificity has to do with pocketpicking the covert removal of a wallet from a pocket or purse in a crowded venue. This crime thrives on a crowd, perhaps more than any other form. As noted earlier, Swedish researchers (Gerell et al., 2020) found that pocket-picking decreased by $61 \%$ in Stockholm during the COVID-affected period when crowd-reduction was especially emphasized. These findings underscore the importance of linking specific changes in routines to specific types of crime.

Theft may also be moving outside of the physical retail structure and developing in areas where officially reported came data is not readily available. For example, before COVID-19 package theft (e.g., packages delivered outside a residence and stolen before the owner can retrieve them) was a growing concern, and few, if any, police agencies kept data on the problem (Stickle, Hicks, Stickle, \& Hutchinson, 2020). However, with entire populations confined to their homes, shopping has shifted virtually, and delivery of products has risen $74 \%$ (ACI, 2020). As a result, the opportunity for theft of packages left unattended at a residence may be increasing (Stickle, 2020a). While more person may be home, daily routine activities have also been interrupted, which impact guardianship. As a result, packages left unattended for extended periods or forgotten altogether (Stickle, 2020b).

These are just a few examples of why examining specific crime types and situations is vital to criminology. It allows the researcher to identify nuanced changes that are important when developing future prevention techniques and to test theoretical tools. There are, no doubt, many factors that are impacting pandemic crime rates, and only by examining them with specificity can researchers achieve an enhanced understanding of crime. 


\section{Temporal Shift}

Temporal understanding of crime is essential because the time of day, day of the week, months, seasons, and other time-related factors are commonly known to impact crime; in other words, crime is not evenly distributed across place or time (Brantingham \& Brantingham, 1995). However, stay-at-home orders that have people living, working, eating, and finding entertainment at home as weekdays merge into weekends may cause time distinctions to blur when speaking of crime. The change in the population's routine behavior, even at home, is already being seen in online browsing habits and television use; behavior has shifted to higher viewing rates on Mondays than on the traditional Saturday (Comcast, 2020). To address these unusual, pandemic-generated changes in routine activities, criminologists need to examine crime rates in a different temporal perspective and consider the context of COVID-19 stay-at-home orders. However, there must be more specificity than a pre and post examination of crime trends, and measurements at the state and even community level are needed to ensure accuracy.

We propose the following seven important periods for identification and comparison of crime rate changes related to the crisis (Table 1).

These measures must be tailored to individual communities or states to coincide with routine activity trends and government orders. Period 1 should be of sufficient time to establish some base levels of crime rates. Period 2 is where the beginning of voluntary behavior changes is likely to be observable, somewhere around mid-February, and extending until the government ordered quarantines for the general population. During this time, as concern swept across the nation, many people chose to alter their lifestyles; schools closed, and other modifications in society likely began to impact crime slowly. For example, an early study of police calls for service by Mohler et al. (2020) found routine activities began to change 8 to 10 days before stay-at-home orders were enacted in Los Angeles, California, and Indianapolis, Indiana, as well as other cities and other nations.

Periods 3 and 4 are contingent on the length of the government-ordered closures. For example, if a state was under stay-at-home orders for 4 weeks, we recommend examining an early period (period 3) as well as a late period (period 4) of two weeks. Dividing the length of stay-at-home orders by half (or more if the order is longer than six weeks) will capture the changes in routine activity as the stay-at-home orders continue. Capturing this data in two or more periods is crucial as the longer the order continues, the more likely people will begin to violate the order, and crime rates may

Table 1 Summary of the changes in routine activities by period, February to May, 2020

\begin{tabular}{ll}
\hline Period approximation & Comments \\
\hline $\begin{array}{l}\text { 1. Before Mid-February } \\
\text { 2. Mid-February to Mid-March }\end{array}$ & $\begin{array}{l}\text { Little change in routine activities } \\
\text { Soft changes in routine activities appear. Important markers include } \\
\text { closure of schools and suggested stay-at-home order }\end{array}$ \\
$\begin{array}{l}\text { Earlier legally imposed stay-at-home orders } \\
\text { 4. Mid-March to Mid-May to End of May }\end{array}$ & $\begin{array}{l}\text { Later legally imposed stay-at-home orders } \\
\text { 5. Ill-defined }\end{array}$ \\
6. Ill-defined & Phased re-opening continues
\end{tabular}


begin to change. For example, early reports in Sweden saw a slight decline in vandalism $(-4 \%)$, followed by a sharp increase after five weeks into the restrictions. There is also likely some relationship between non-compliance and crime as Nivette et al. (2020) found non-compliance with stay-at-home orders was associated with delinquent behavior. While early reports have not identified the same trends in the US, news reports during the month of May (Koetsier, 2020) indicated that a large number of persons were emerging from homes before an official end to the stay-athome orders. A rise in crime may be detected because it is possible that the longer the orders continue, the less effective they become.

Lastly, periods 5 and 6 are difficult to define as the situation is still unfolding at the time of this publication, as a complete rescinded stay-at-home order has not occurred to date. Moreover, it is also critical to consider that many individuals who live in an area where the stay-at-home orders have been partially revoked may still choose not to return to their daily lives (see a news report by Schaul et al., 2020). This is why it will be important to capture data starting at the point of a rescinded stay-at-home order and by measuring crime rates every few weeks after that for an extended period. These periods may coincide with the phased re-opening plan followed by many governments (see CDC, 2020) or within a timeframe for several weeks each, which may result in the need to add continued periods of crime data.

Criminologists do not have to rely on the assumption that people follow stay-athome orders. For the first time, Mobility Trend Reports are being offered free (including in CSV format) by both Google (2020) and Apple (2020). These reports offer aggregated movement data based on anonymized cell phone location history at the national, state, and county levels. The data includes daily reports and includes inferred locations (i.e., retail, grocery, parks, transit, residential, workplace). With this data, it is possible to compare societal behavior within these recommended periods and gain a more accurate picture of where people were and importantly when they were there. Combined with the ability to measure compliance with movement restrictions, criminologists have the data to examine the routine activities of whole populations at a level never before possible while overlaying crime rates for both a temporal a place-based evaluation.

\section{Place-Based}

Studying crime based at a place is another critical part of understanding not only crime trends but also methods to disrupt crime (Eck \& Weisburd, 2015). Under the current circumstances with people's daily routine disrupted, this is even more important as people shift to more time within the home, the opportunities and places for offenders and victims to meet become limited. As a result, there is likely far less crime as people; both victims and offenders are not together in a place for the crime to occur.

To illustrate, consider workplace violence and crime. With a significant number of persons at home, rather than work, there is a reduced opportunity for offenders to assault co-workers. Similarly, there is less opportunity for a victim to have a phone stolen from the breakroom. It is important to remember that during the COVID-19 crisis, variables commonly related to many other criminological theories (i.e., poverty, stress, self-control) have not changed to such a degree to explain the sharp reduction in crime. Instead, the opportunity to be connected to a victim in time and place appears to 
be the most significant variable that has led to a marked reduction in the workplace and other place-based crimes.

However, in some regards, this place-based shift may result in increased crime rates in other areas (Roberts, 2020). For example, while digital, the internet can be classified as a 'place' or medium for victimization to occur (Machimbarrena et al., 2018). Under the COVID-19 stay-at-home orders, people are spending significantly more time online. By late March, for example, cable internet usage, as reported by The Internet and Television Association (2020), surged more than $30 \%$ and continued to grow until mid-April, which appears to coincide with many of the stay-at-home orders. The increased time using the internet likely leads to more opportunities for cybercrimes to occur as the victim's virtual presence has shifted dramatically (e.g., away from place-based crime at work or school and to place-based crime online). Additionally, offenders may have also been impacted by the COVID-19 stay-at-home orders and have increased time to identify victims.

Shifting back to a physical place and crimes, it is also important to evaluate land usage and population density when considering crime trends. There are emerging trends in the new COVID-19 crime data suggesting crime differences in certain places (Ashby, 2020a). For example, public places such as stores, restaurants, and entertainment areas are experiencing sharp decreases in some types of crime (Pietrawska et al., 2020a), while crime in the home may be remaining consistent (Campbdelli, 2020; Payne \& Morgan, 2020; Shayegh \& Malpede, 2020, and mix-land use may see relatively stable or slightly increasing crime rates (Felson et al., 2020). Here again, routine activities and rational choice perspectives may explain much of the crime in these places. For instance, entertainment businesses and districts, along with dine-in restaurants, were generally closed during the orders. Thus, with fewer offenders routinely in these places and fewer victims present, crime will naturally decline. However, a reasoning offender (Cornish \& Clarke, 2014) may choose to target areas with fewer people (i.e., guardians) such as closed malls, business parks, and other places that may see an increase in property crimes. Additionally, mixed land usage, especially in population-dense areas, may allow an offender to travel in areas unnoticed easily and, therefore, present opportunities for crime (Felson et al., 2020).

Place, whether virtual or physical, is a crucial factor in crime. The COVID-19 crisis has re-shaped the places that persons routinely visit, increasing some-home and online, while decreasing others - work, retail, school, and entertainment. Highlighting the role that place has played in crime rates during the pandemic should influence how criminologists study crime in a post-pandemic world and lead to further crime reduction through place-based prevention techniques.

\section{Data-Driven}

We have listed some initial findings on crime in the COVID-19 era and also described the need to study crime specifically, temporally, and place-based. Next, we will discuss data for measuring crime. One problem in criminology, as in other social science fields, is there are too many variables, too little variation, or an inability to control for specific variables. However, in the current pandemic, these problems decrease dramatically, and criminologists should take advantage of the favorable conditions and abundant data.

First, as described in the introduction, few variables changed during the first several weeks of the pandemic. The most substantial change has been the stay-at-home orders, 
which impacted the routine activities of entire populations. With so few variables changed, it should be easier to identify and measure significant and substantial changes in crime. Second, the variation in crime rates has been drastic. On the order of $10 \%, 20 \%$, and even sometimes $60 \%$ transformation of crime patterns. These significant measurable changes allow researchers to see 'past' other variables that have little impact and focus on the significant variables impacting crime. Third, with entire populations affected by the pandemic, there is little need for controlling traditional variables such as age, gender, education, social status, and more. The impacted population is closer to the entire population rather than a 'sample population,' which means it is possible to move beyond inferential statistics and measure the actual change in the whole population.

Another challenge for criminologists is crime data. We encourage the use of four broad categories of data, including official police reports, victim and other self-report surveys, private or anecdotal data, and public data. Police data is an essential source during the pandemic. However, with many agencies experiencing workforce-related issues during the pandemic and purposely reducing the person-to-person contact to reduce the risk of virus spread, the official police data may underreport crime more than usual. Further, with more persons staying inside and not venturing out to school and work, other crimes, such as intimate partner violence and abuse of children, may not be captured through traditional reporting means. Therefore, it will be important that victim and self-report surveys continue to be used to help capture data that official reports do not (see Krohn, Thornberry, Gibson, \& Baldwin, 2010).

Other sources of direct crime data and ancillary sources are often overlooked. Ancillary sources of data can take the form of calls to abuse hotlines, reports on consumer spending, internet traffic, police call for service, hospital mandatory reporting on specific injuries, and the Bureau of Labor Statics (2020) data on injuries resulting from violence at the workplace. Additionally, sources from private companies also provide insight into crime not always reported through official channels. For example, many retail organizations release data on crime within their stores, credit card companies release fraud statistics, and insurance organizations publish claims related to crime victimization. These sources may be particularly important as many areas where crime is occurring during the COVID-19 crisis are within private spaces, and obtaining non-police data is essential to understanding the crime shift. Lastly, other publicly available resources should be included in the analysis as well. Specifically, Mobility Trend Reports by Apple and Google, which provide detailed information on population location daily that the county level. This data set, never before publicly provided, should be used to overlay with other data (see Mohler et al., 2020).

Moving beyond the data to the methods, the circumstances of the COVID-19 crisis has led to a naturally occurring quasi-random control trial. Because each state-issued stay-at-home order at different times, under different circumstances, and rescinded them at different dates, it is possible to compare crime across many population groups. For example, Kentucky issued an order on March 26th and entered phased re-opening on May 11th (47 days) while neighboring state Tennessee waited seven more days, issuing a stay-at-home order on March 31st, and began a phased re-opening on April 27 th, fourteen days ahead of its neighbor. These states, which share many demographic similarities, are ideal for comparison.

In addition to the unequal start and stop dates for state-wide lock-downs, the activities limited by the orders varied as well; for instance, some states kept parks open while others 
closed them. Similarly, some states outlawed gatherings of 10 or more, while other states established different criteria. The response to alcohol also creates a valuable point in data analysis. Examples abound of states that relaxed laws on alcohol sales, such as Kentucky, which allowed for the first-time home delivery of alcohol and service of alcohol with food take-out orders during the crisis (Minton, 2020). On the other end of the spectrum, some states deemed alcohol 'non-essential' but changed course after public backlash. For example, Pennsylvania initially closed liquor stores and created a cascade of persons traveling outside the state seeking alcohol (Thomas, 2020). Conditions such as these either between states or even within states are plentiful and provide essential data points that allow for an excellent comparison of crime and related factors.

\section{The Largest Criminological Experiment in History}

There is little doubt that the COVID-19 crisis will impact history on a scale not seen since WWII. Provisional insights indicate that a substantial drop in crime is occurring around the world and within the US. However, these reports also indicate the changes are not even across time, place, or crime type. Therefore, we encourage criminologists to study this crisis through the use of new and existing sources of crime data, with a specificity of crime types, in a temporal fashion, and placed based.

Moreover, the leading feature of these crime changes will be that the government ordered stay-at-home mandates, which impacted the routine activities of entire populations. The variation in these orders by state and community regarding when the orders were implemented and rescinded and what restrictions were in place has provided a naturally occurring, quasi-randomized control experiment. For example, researchers can compare states and communities that released prisoners early, increased or reduced alcohol availability, began lock-downs early, crime in public places as opposed to residential and mixed land use, and operationalize many variables that were previously intangible or inarticulable.

The findings emerging from the COVID-19 crisis will impact criminological theories for the next several decades. We encourage researchers to embark on in-depth explorations of the data made available from the pandemic and to search for not only why, where, when, and to what extent crime fell, but also how to use this knowledge for practical applications after the world returns to 'normal' and concludes this experiment in crime reduction and extraordinary test of human determination and resiliency.

Funding Information No funding was received for this research.

\section{Compliance with Ethical Standards}

Conflicts of Interest The authors report no conflicts of interest.

\section{References}

ACI (2020). COVID-19 crisis driving changes in ecommerce purchasing behaviors, ACI Worldwide Research Reveals: https://www.aciworldwide.com/news-and-events/press-releases/2020/april/covid-19-crisisdrives-changes-in-ecommerce-sales-aci-worldwide-research-reveals 
Apple Inc. (2020). COVID-19 - Mobility trends reports. https://www.apple.com/covid19/mobility

Ashby, M. P. J. (2020a). Initial evidence on the relationship between the coronavirus pandemic and crime in the United States. Crime Science, 9(6). https://doi.org/10.1186/s40163-020-00117-6.

Ashby, M. P. J. (2020b). Changes in police calls for service during the early months of the 2020 coronavirus pandemic. https://doi.org/10.31235/osf.io/h4mcu

Brantingham, P., \& Brantingham, P. (1995). Criminality of place. European journal on criminal policy and research, 3(3), 5-26.

Bureau of Labor Statistics (2020). News release, Bureau of Labor Statics US Department of Labor: The Employment Situation - April 2020. https://www.bls.gov/news.release/pdf/empsit.pdf

Campedelli, G. M., Aziani, A., \& Favarin, S. (2020). Exploring the effect of 2019-nCoV containment policies on crime: The case of los angeles. arXiv preprint arXiv:2003.11021.

Center for Disease Control (2020). Guidelines opening up American again. https://www.whitehouse. gov/openingamerica/

Clarke, R. V. G., \& Felson, M. (Eds.). (1993). Routine activity and rational choice (Vol. 5). Transaction publishers.

Cohen, L. E., \& Felson, M. (1979). Social change and crime rate trends: A routine activity approach. American Sociological Review, 44, 588-608.

Comcast (2020). COVID-19 TV habits suggest the days are blurring together. https://corporate.comcast. com/stories/xfinity-viewing-data-covid-19

Cornish, D. B., \& Clarke, R. V. (Eds.). (2014). The reasoning criminal: Rational choice perspectives on offending. Transaction Publishers.

Eck, J., \& Weisburd, D. L. (2015). Crime places in crime theory. Crime and place: Crime prevention studies, 4.

Fattah, E. A. (2020). A social Scientist's look at a global crisis: Reflections on the likely positive impact of the Corona virus. Special Paper: School of Criminology, Simon Fraser University, Burnaby, BC, Canada.

Felson, M., Jiang, S., \& Xu, Y. (2020). Research note: Routine activity effects of the COVID-19 pandemic on burglary in Detroit, March 2020.

Gerell, M., Kardell, J., \& Kindgren, J. (2020). Minor COVID-19 association with crime in Sweden, a five week follow up. Malmo University https://osf.io/preprints/socarxiv/w7gka/.

Google (2020). COVID-19 Community Mobility Report. https://www.google.com/covid19/mobility/

Jahshan, E. (2020). Retail footfall declines at sharpest rate in march. Retail Gazette: https://www.retailgazette. co.uk/blog/2020/04/retail-footfall-declines-at-sharpest-rate-in-march/

Koetsier, J. (2020). Apple data shows shelter-in-place is ending, whether governments want it to or not. Forbes. https://www.forbes.com/sites/johnkoetsier/2020/05/01/apple-data-shows-shelter-in-place-isending-whether-governments-want-it-to-or-not/\#6e35fbdd6fb5.

Krohn, M. D., Thornberry, T. P., Gibson, C. L., \& Baldwin, J. M. (2010). The development and impact of self-report measures of crime and delinquency. Journal of Quantitative Criminology, 26(4), 509-525.

LeClerc, B., \& Wortley, R. (Eds.). (2013). Cognition and crime: Offender decision making and script analyses. Routledge.

Lum, C., Maupin, C., \& Stoltz, M. (2020). The impact of COVID-19 on law enforcement agencies (wave 1). International Association of Chiefs of police. https://www.theiacp.org/sites/default/files/IACP-GMU survey.Pdf.

Machimbarrena, J. M., Calvete, E., Fernández-González, L., Álvarez-Bardón, A., Álvarez-Fernández, L., \& González-Cabrera, J. (2018). Internet risks: An overview of victimization in cyberbullying, cyber dating abuse, sexting, online grooming and problematic internet use. International Journal of Environmental Research and Public Health, 15(11), 2471.

Minton, M. (2020). Cocktails in quarantine: How your state governs booze buying during lock-down. (2020). Competitive Enterprise Institute: https://cei.org/blog/cocktails-quarantine-how-your-state-governs-boozebuying-during-lockdown

Mohler, G., Bertozzie, A. L., Carter, J., Short, M. B., Sledge, D., Tia, G. E., Uchida, C., D., and Brantingham, P. J. (2020). Impact of social distancing during COVID-19 pandemic on crime in Los Angeles and Indianapolis. Journal of Criminal Justice, 101692.

Nivette, A., Ribeaud, D., Murray, A. L., Steinhoff, A., Bechtiger, L., Hepp, U., Shanahan, L., \& Eisner, M. (2020). Non-compliance with COVID-19-related public health measures among young adults: Insights from a longitudinal cohort study. https://doi.org/10.31235/osf.io/8edbj

Payne, J., \& Morgan, A. (2020). Property Crime during the COVID-19 Pandemic: A comparison of recorded offence rates and dynamic forecasts (ARIMA) for March 2020 in Queensland, Australia.

Pietrawska, B., Aurand, S. K. \& Palmer, W. (2020a) Covid-19 and crime: CAP's perspective on crime and loss in the age of Covid-19: Los Angeles crime. CAP Index, Issue 19.2. 
Pietrawska, B., Aurand, S. K. \& Palmer, W. (2020b) Covid-19 and crime: CAP's perspective on crime and loss in the age of Covid-19: Crime in Los Angeles and Chicago during Covid-19. CAP Index, Issue 19.3.

Pietrawska, B., Aurand, S. K. \& Palmer, W. (2020c) Covid-19 and crime: CAP's perspective on crime and loss in the age of Covid-19: Crime in Los Angeles and Chicago during Covid-19. CAP Index, Issue 19.4.

Roberts, K. (2020). Opportunity knocks: How crime patterns can change during a pandemic. Australian Institute of Police Management. https:/www.aipm.gov.au/karl-roberts-opportunity-knocks-coronavirus

Schaul, K., Mayes, B. R., \& Berkowitz, B. (2020). Where Americans are still staying at home the most. The Washington Post. https://www.washingtonpost.com/graphics/2020/national/map-us-still-staying-homecoronavirus/

Shayegh, S., \& Malpede, M. (2020). Staying Home Saves Lives, Really! In Staying home saves lives, really!. RFF-CMCC European Institute on Economics and the Environment. https://doi.org/10.2139 /ssrn.3567394.

Stickle, B. (2020a) Porch piracy: Here's what we learned after watching hours of YouTube videos showing packages being pilfered from homes. The Conversation: https://theconversation.com/porch-piracy-hereswhat-we-learned-after-watching-hours-of-youtube-videos-showing-packages-being-pilfered-from-homes132497

Stickle, B. (2020b). Package theft in a pandemic. Jill Dando Institute of Security and Crime Science: University College London https://www.ucl.ac.uk/jill-dando-institute/sites/jill-dandoinstitute/files/package_theft_in_a_pandemic_final_no_15_pdf.

Stickle, B., Hicks, M., Stickle, A., \& Hutchinson, Z. (2020). Porch pirates: Examining unattended package theft through crime script analysis. Criminal Justice Studies, 33(2), 79-95.

The Internet \& Television Association (2020). COVID-19: How cable's internet networks are performing. NCTA: https://www.ncta.com/COVIDdashboard

Thomas, C. (2020). Pa.'s closure of its liquor stores sends a 'tsunami' of business across state lines. PatriotNews: https://www.pennlive.com/business/2020/04/border-bleed-pennsylvanians-are-making-tracks-toget-their-booze-during-fine-wine-good-spirits-stores-coronavirus-closure.html

Washington Post-ABC News (2020). Retrieved from: https://context-cdn.washingtonpost. com/notes/prod/default/documents/5ff24ba7-0686-4393-b2fe-86c39447bc9d/note/943d692c-f812-4ec3a0a7-cabd64d36d4b.\#page=1

Publisher's Note Springer Nature remains neutral with regard to jurisdictional claims in published maps and institutional affiliations.

Ben Stickle is an Associate Professor of Criminal Justice Administration at Middle Tennessee State University. He holds a Ph.D. in Justice Administration from the University of Louisville. Ben has nearly twenty years of law enforcement and private security experience. He has published several scholarly journal articles, book chapters, and a book. Ben's research interests include policing, crime prevention, and property crime (metal theft \& package theft).

Marcus Felson originated the routine activity approach to crime rate analysis. He is an expert in how to think about crime in very tangible terms and how to reduce it using such thinking. His books include Crime and Nature (Sage, 2006) as well as Crime and Everyday Life, now in its sixth edition. His work is increasingly applied to crime reduction and to explain diverse crime problems, including gangs, drug sales, robberies, burglaries, fights, organized crime, and cybercrime. 